\title{
Dispersing hydrophilic nanoparticles in hydrophobic polymers: \\ HDPE/ZnO nanocomposites by a novel template-based approach
}

\author{
M. Salzano de Luna ${ }^{1}$, M. Galizia ${ }^{1}$, J. Wojnarowicz ${ }^{2}$, R. Rosa ${ }^{3}$, W. Lojkowski ${ }^{2}$, C. Leonelli ${ }^{3}$, \\ D. Acierno ${ }^{1}$, G. Filippone ${ }^{1 *}$ \\ ${ }^{1}$ Dipartimento di Ingegneria Chimica, dei Materiali e della Produzione Industriale, Università di Napoli Federico II, \\ Piazzale Tecchio 80, 80125 Naples, Italy \\ ${ }^{2}$ Institute of High Pressure Physics, Polish Academy of Sciences, ul. Sokolowska 29/37 01-142 Warsaw, Poland \\ ${ }^{3}$ Dipartimento di Ingegneria 'Enzo Ferrari', Università di Modena e Reggio Emilia, Via Vignolese 905/A, 41125 Modena, \\ Italy
}

Received 3 November 2013; accepted in revised form 29 December 2013

\begin{abstract}
The efficiency of a novel template-based approach for the dispersion of hydrophilic nanoparticles within hydrophobic polymer matrices is investigated. The procedure envisages the permeation of a well dispersed nanoparticle suspension inside a micro-porous matrix, obtained through selective extraction of a sacrificial phase from a finely interpenetrated co-continuous polymer blend. Specifically, a blend of high density polyethylene (HDPE) and polyethylene oxide (PEO) at $50 / 50 \mathrm{wt} \%$ is prepared by melt mixing. The addition of small amounts of organo-clay promotes the necessary refinement of the blend morphology. Once removed the PEO, the micro-porous HDPE matrix is dipped in a colloidal suspension of zinc oxide nanoparticles which exhibits low interfacial tension with HDPE. A system prepared by traditional melt mixing is used as reference. Melt- and solid-state viscoelastic measurements reveal a good quality of the filler dispersion despite the uneven distribution on micro-scale. The latter can be capitalized to minimize the filler content to attain a certain improvement of the material properties or to design nano-structured polymer composites.
\end{abstract}

Keywords: nanocomposites, $\mathrm{ZnO}$ nanoparticles, filler dispersion, polymer blends, templates

\section{Introduction}

Polymer nanocomposites (PNCs) based on inorganic nanoparticles (INPs) are a well-established field of research due to the interesting properties arising from such class of filler. In particular, besides improved mechanical, thermal and barrier properties, the control of the chemistry of INPs may provide new functionalities to the host matrix, allowing for the enlarging of the fields of application of polymeric materials in sectors such as automotive, micro-optics, micro-electronics, environment, health, energy and housing [1]. The use of nanoparticles as filler for polymer matrices generally implies relevant problems in terms of dispersability [2]. INPs usually present hydrophilic characteristics, which bring about substantial differences in terms of surface energy between the polymer matrix and the filler, leading to phase segregation. In addition, the high surface-to-volume ratio of nanoparticles typically results in small inter-particle distances, which makes van der Waals and electrostatic forces of major importance [3]. As a consequence, nanoparti-

\footnotetext{
${ }^{*}$ Corresponding author, e-mail: gfilippo@unina.it

(C) BME-PT
} 
cles are inclined to form agglomerates which can be extremely difficult to break up into individual species and to disperse uniformly inside the polymer matrix. The presence of such agglomerates impedes the efficient transfer of the beneficial properties of the filler related to its nanoscopic dimension to the host polymer, leading to 'nanofilled materials' with properties comparable to traditional microcomposites [4].

In the light of previous considerations, it is clear that controlling the dispersion of nanoparticles inside polymer matrices is crucial to fully exploit the potential of polymer nanocomposites. In this sense, the using of suitable compounding technique is strictly required [5]. Various approaches have been proposed to manufacture well dispersed INP-based polymer nanocomposites. Chemical modification of the nanoparticle surface, polymer-particle compatibilizing agents, in situ INP synthesis and/or polymerization are examples of possible strategies which have revealed to be effective in attaining a homogeneous filler dispersion [6-8]. However, the compounding approach for the large scale production of PNCs typically involve unmodified nanoparticles which are directly incorporated in the polymer matrix, either in the melt or in solution. Melt mixing is the most time- and cost-effective technique, but it requires that the filler is used in powder form. Although produced in the nm-range and with a narrow size distribution, such kind of dry nanoparticles have the tendency to fuse together forming stable aggregates, suffering from further agglomeration during handling and/or storage [9]. The immediate advantage offered by solution mixing is a better filler dispersion [10]. In this case the nanoparticles are in the form of colloidal dispersion, in which almost exclusively isolated primary particles are present. The major con of solution mixing is that it requires that the polymer matrix is dissolved in the same solvent of nanoparticles or in a medium soluble with them. Unless often unaffordable chemical modifications of the particle surface are made, the feasibility of solution mixing is hence limited to suitable polymer-particle pairs, and to polymers which are soluble in solvents of common use, thereby excluding, for example, polyolefins.

In the present work we deal with the challenging task of dispersing hydrophilic nanoparticles in a hydrophobic matrix. In particular, PNCs based on high density polyethylene (HDPE) filled with zinc oxide $(\mathrm{ZnO})$ nanoparticles are prepared by means of a novel template-based approach, which capitalizes the high degree of filler dispersion of solution techniques eluding the issues related to the needing of specific solvents for the polymer. The ability of the proposed strategy to effectively entrap hydrophilic nanoparticles in a hydrophobic polymer matrix is the result of a judicial selection of the materials and compounding procedures. The state of dispersion and distribution of the filler is compared to that of PNCs prepared by conventional melt mixing.

\section{Experimental \\ 2.1. Materials}

The polymers are high density polyethylene (HDPE, code 427985, Sigma-Aldrich, Milan, Italy) with melt flow index $\mathrm{MFI}_{190^{\circ} \mathrm{C} / 2.16 \mathrm{~kg}}=12 \mathrm{~g} \cdot \mathrm{min}^{-1}$ and poly (ethyleneoxide) (PEO, code 181986, Sigma-Aldrich, Italy) with molecular weight $M_{\mathrm{v}}=100 \mathrm{kDa}$.

A montmorillonite organo-modified with dimethyl dihydrogenatedtallow quaternary ammonium salt (Cloisite ${ }^{\circledR}$ C15A, Southern Clay Products, Gonzales, Texas, USA) was used to refine the morphology of the polymer blends. C15A has an organic content of $\sim 43 \%$ and a mass density of $1.66 \mathrm{~g} \cdot \mathrm{cm}^{-3}$.

Unfunctionalized, almost spherical zinc oxide nanoparticles were produced in the form of dry powder by microwave-assisted synthesis [11], with average dimension of the primary particles of $32 \mathrm{~nm}$, specific surface area of $\sim 36 \mathrm{~m}^{2} \cdot \mathrm{g}^{-1}$ (BET method) and mass density of $5.21 \mathrm{~g} \cdot \mathrm{cm}^{-3}$.

Two colloidal suspensions of zinc oxide nanoparticles were purchased from Sigma Aldrich: a waterbased dispersion of particle of size $<100 \mathrm{~nm}(50 \mathrm{wt} \%$ of $\mathrm{ZnO}$, code 721077) and a dispersion of particle of size $<110 \mathrm{~nm}$ in butyl acetate $(40 \mathrm{wt} \%$ of $\mathrm{ZnO}$, code 721093).

\subsection{Nanocomposite preparation}

Two series of nanocomposites at different filler content were prepared using different compounding procedures. The samples classified as 'MM' were prepared by a two-step melt mixing route. Specifically, a masterbatch of HDPE at high content of dry $\mathrm{ZnO}$ nanoparticles (particle weight percentage $\Phi_{\mathrm{ZnO}} \sim 7 \mathrm{wt} \%$ ) was prepared using a co-rotating conical twin-screw micro-compounder (Xplore, DSM). The resulting sample was then diluted by melt mixing with neat HDPE to adjust the composition. The extrusions were all performed at $150^{\circ} \mathrm{C}$ in 
nitrogen atmosphere at a screw speed of $200 \mathrm{rpm}$, corresponding to average shear rates of $\sim 75 \mathrm{~s}^{-1}$. Finally, the specimens for the subsequent analyses were obtained by compression molding for $3 \mathrm{~min}-$ utes at $150^{\circ} \mathrm{C}$ under a pressure of $\sim 100$ bar. The unfilled HDPE used as reference material was processed in the same conditions.

The second class of samples, classified as 'TB' (template-based), was prepared by a novel approach in which a polymer scaffold is used as template. The basic steps are sketched in Figure 1. First, a HDPE/ PEO blend $(50 / 50 \mathrm{wt} \%)$ filled with C15A $\left(\Phi_{\mathrm{C} 15 \mathrm{~A}}\right.$ $\sim 1.5 \mathrm{wt} \%$ ) was prepared by melt mixing at $150^{\circ} \mathrm{C}$ in nitrogen atmosphere ad at a screw speed of $100 \mathrm{rpm}$, corresponding to average shear rates of $\sim 50 \mathrm{~s}^{-1}$ (step a) in Figure 1. The constituents, dried overnight under vacuum at $50^{\circ} \mathrm{C}$, were simultaneously loaded and melt compounded in the extruder. Disk-shaped specimens were obtained by compression-molding at $150^{\circ} \mathrm{C}$ for 3 minutes under a pressure of $\sim 100$ bar. Then, the disks were immersed in deionized water for approximately 3 weeks under stirring to extract the PEO phase from the samples (step b). The two as-received dispersions of $\mathrm{ZnO}$ nanoparticles in water and butyl acetate were diluted with pure solvents until reaching a filler concentration of $\sim 4 \mathrm{wt} \%$. Then, the extracted, PEO-free disks were dipped in the dispersions under stirring to allow the $\mathrm{ZnO}$ to penetrate inside the microporous HDPE scaffolds (step c). After 2 weeks the samples were collected and dried under vacuum until a constant weight was reached. The TB approach led to porous samples, which were finally compacted at $150^{\circ} \mathrm{C}$ in a vacuum oven under low
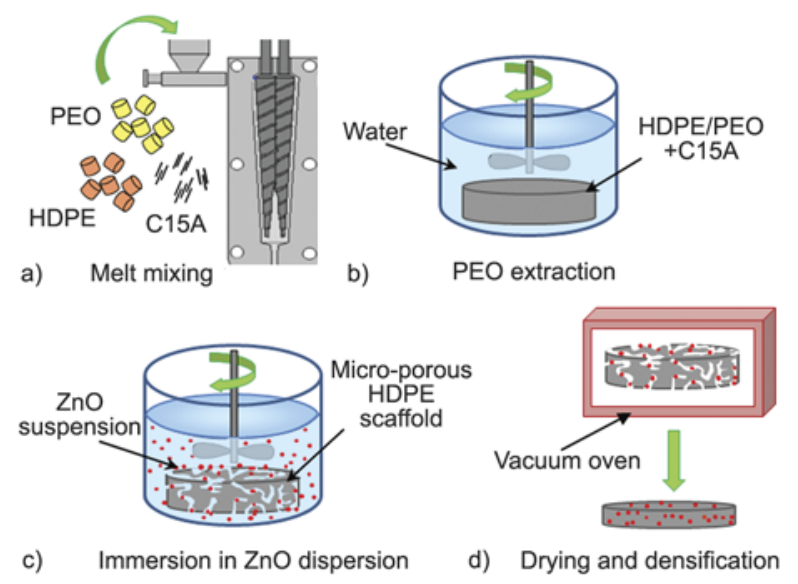

Figure 1. Schematic of the basic steps of the templatebased approach for the preparation of the HDPE/ $\mathrm{ZnO}$ nanocomposites pressures ( $\sim 0.1$ bar $)$ to obtain dense samples (step d).

HDPE-based nanocomposites filled with C15A $\left(\Phi_{\mathrm{C} 15 \mathrm{~A}} \sim 1.5 \mathrm{wt} \%\right)$ and with the same amount of $\mathrm{ZnO}$ nanoparticles as those obtained by the TB approach were prepared by simple melt mixing and used as reference to assess the effectiveness of our compounding technique.

\subsection{Characterization}

Differential scanning calorimetry was performed under nitrogen flow using a Q20 DSC apparatus (TA Instruments). The samples were first heated from room temperature up to $170^{\circ} \mathrm{C}$, then cooled down to $25^{\circ} \mathrm{C}$, and finally heated again. Each step was performed at a rate of $10^{\circ} \mathrm{C} \mathrm{min}{ }^{-1}$. The crystallization temperature $\left(T_{\mathrm{c}}\right)$, onset $\left(T_{\mathrm{m}, \text { onset }}\right)$ and peak melting temperatures $\left(T_{\text {m,peak }}\right)$ and melting enthalpy $\left(\Delta H_{\mathrm{f}}\right)$ were recorded. The degree of crystallinity $\left(\chi_{c}\right)$ of the HDPE samples was obtained by dividing the $\Delta H_{\mathrm{f}}$ of the first heating scan by the melting enthalpy of a $100 \%$ pure crystalline HDPE sample, taken as $293.1 \mathrm{~J} \cdot \mathrm{g}^{-1}$ [12].

The tensile properties were estimated at room temperature and humidity using an Instron machine according to ASTM test method D882. The specimens were cut from compression-molded sheets. The samples, stored at room temperature and humidity, were tested at $25 \mathrm{~mm} \cdot \mathrm{min}^{-1}$ up to a strain of $2 \%$, then the speed was increased up to $50 \mathrm{~mm} \cdot \mathrm{min}^{-1}$ until break. The Young's modulus $(E)$, tensile strength $\left(\sigma_{\max }\right)$ and elongation at break $\left(\varepsilon_{\text {break }}\right)$ were recorded. The data reported are average values obtained by analyzing the results of eight tests per sample.

The permeability to oxygen $\left(P_{\mathrm{O}_{2}}\right)$ and carbon dioxide $\left(P_{\mathrm{CO}_{2}}\right)$ were measured at $30^{\circ} \mathrm{C}$ and atmospheric pressure using a constant volume-variable pressure apparatus.

Thermogravimetric analyses were performed using a Q5000 TGA apparatus (TA Instruments). The samples were heated up to $700^{\circ} \mathrm{C}$ at $10^{\circ} \mathrm{C} \cdot \mathrm{min}^{-1}$ in nitrogen atmosphere. The actual content of filler in the PNCs was estimated as the residual weight at $T=700^{\circ} \mathrm{C}$. Note that for the TB samples the actual content of filler was determined after each step of Figure 1.

The microstructure of the neat and filled HDPE/ PEO blends was investigated through scanning electron microscopy (FE-SEM, Ultraplus by Zeiss). The samples were cracked in liquid nitrogen and 
the fracture surfaces were observed. Energy dispersive spectroscopy (EDS, Aztec by Oxford Instruments) was used to infer the presence of the $\mathrm{ZnO}$ nanoparticles in the samples obtained by TB approach and to investigate the distribution of the filler on micro-scale.

The static contact angle $(\theta)$ of water and butyl acetate on HDPE films surface was estimated with an automatic video-based measurement of contact angle performed at room temperature and humidity by using a Theta contact angle T200-Auto (KSV/ Attension, Helsinki). Five $\mu \mathrm{L}$ of liquid were placed over the HDPE surface and the Young/Laplace method was used to calculate the static contact angle. Five independent measurements were performed for each liquid.

A stress-controlled rotational rheometer (AR-G2, TA Instruments) in parallel-plate geometry (diameter $25 \mathrm{~mm}$ ) was used for the rheological analyses. Oscillatory tests were performed at $T=180^{\circ} \mathrm{C}$ in a dry nitrogen atmosphere. Specifically, low-frequency $\left(10^{-1} \mathrm{rad} / \mathrm{s}\right)$ time-sweep experiments were carried out first. After the reaching of the steady state, the elastic $\left(G^{\prime}\right)$ and viscous $\left(G^{\prime \prime}\right)$ shear moduli were measured as a function of mechanical frequency $(\omega)$ in the linear regime, which was previously evaluated for each composition through strain amplitude tests.

Dynamic mechanical analyses were carried out using a Tritec 2000 DMA apparatus (Triton Technology Ltd., Grantham). The elastic $\left(E^{\prime}\right)$ and viscous $\left(E^{\prime \prime}\right)$ flexural moduli were measured as func-

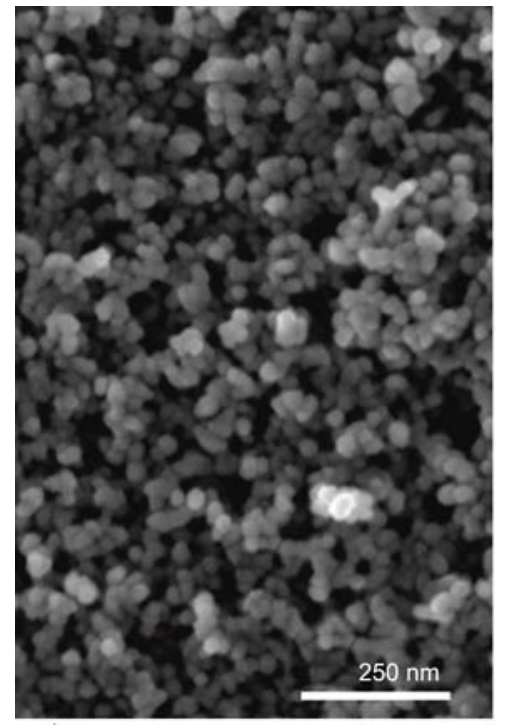

a) tion of temperature in single-cantilever bending mode at a frequency of $1 \mathrm{~Hz}$ and with a total displacement of $0.02 \mathrm{~mm}$, which is small enough to be in the linear regime. The sample bars $\left(10 \times 20 \times 1 \mathrm{~mm}^{3}\right)$ were heated at $2^{\circ} \mathrm{C} \cdot \mathrm{min}^{-1}$ from room temperature.

\section{Results and discussion}

\subsection{Melt mixing route}

First of all, the impact of dry $\mathrm{ZnO}$ nanoparticles on technologically relevant properties of HDPE/ZnO nanocomposites prepared by a traditional melt mixing route has been investigated. Dispersing metal oxide nanoparticles in polymer media is a difficult task because of the large specific surface area of the filler and the incompatibility in surface characteristics with the matrix. Simply compounding polymer and dry nanopowders by melt mixing routes is often inadequate, although the high shear and elongational stresses during extrusion could break the clusters of primary nanoparticles reducing their average size. The minimum size of the aggregates depends on the applied stress and the composite Hamaker constant for two surfaces interacting through a medium [13], being in any case much larger than the size of the single nanoparticle. A SEM micrograph of our dry $\mathrm{ZnO}$ nanoparticles is shown in Figure $2 \mathrm{a}$, whereas a typical micron-sized aggregate suspended in the HDPE matrix of a MM sample is reported in Figure 2b.

The negligible polymer-particle enthalpic interactions and the aggregated state of the filler are expected to not appreciably affect the macroscopic

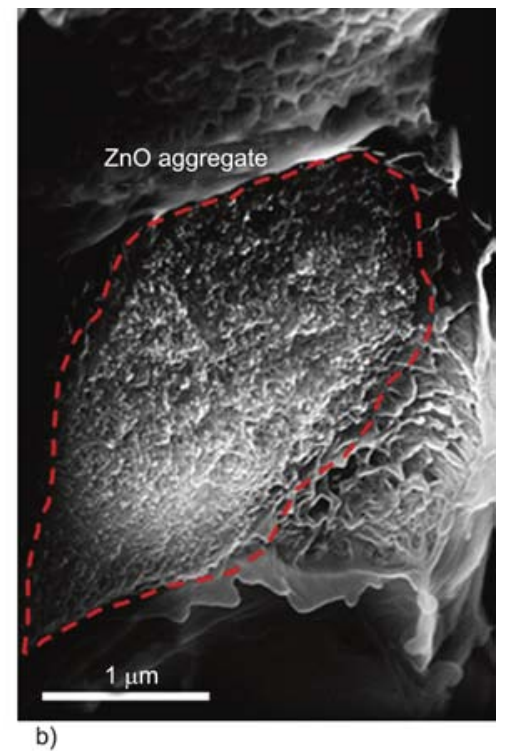

b)

Figure 2. SEM micrographs showing (a) as-synthesized $\mathrm{ZnO}$ dry nanoparticles and (b) a detail of particle aggregate protruding from the fracture surface of a MM nanocomposite 
properties of the MM samples. First, possible effects of the particles on the crystalline structure of the host polymer have been investigated through DSC measurements. As summarized in Table 1, whatever the content of $\mathrm{ZnO}$ nanoparticles is, the melting and crystallization behaviors remain almost constant. In addition, no evident changes are detected for the crystallinity, the samples sharing comparably high values of $\chi_{\mathrm{c}}(\sim 50 \%)$.

Other technologically relevant properties of PNCs particularly sensitive to the state of dispersion of nanoparticles are mechanical and barrier properties. The results of the tensile and permeability tests are reported in Figure 3 as a function of filler content.

Neither $E$ nor $\sigma_{\max }$ appreciably change with respect to the unfilled matrix, whereas a drastic decrease of $\varepsilon_{\text {break }}$ occurs with increasing $\Phi_{\mathrm{ZnO}}$. The detrimental effect on the elongation at break noticed in the presence of the filler is due to the presence of nanoparticle aggregates, which are sites where cracks initiate on and significantly lowering the ultimate properties of the material [14]. The barrier properties are also negligibly affected by the aggregated filler. The $P_{\mathrm{O}_{2}}$ and $P_{\mathrm{CO}_{2}}$ of our MM nanocomposites indeed slightly increase upon addition of $\mathrm{ZnO}$ nanoparticles, probably due to the scarce polymer-particle interfacial adhesion which enhances the overall

Table 1. Onset and peak melting temperatures, crystallization temperature and crystallinity of neat HDPE and melt mixed nanocomposites

\begin{tabular}{|c|c|c|c|c|}
\hline $\begin{array}{c}\mathbf{\Phi}_{\text {ZnO }} \\
{[\mathbf{w t} \mathbf{0}]}\end{array}$ & $\begin{array}{c}\mathbf{T}_{\mathbf{m}, \mathbf{o n s e t}} \\
{\left[{ }^{\circ} \mathbf{C}\right]}\end{array}$ & $\begin{array}{c}\mathbf{T}_{\mathbf{m}, \mathbf{p e a k}} \\
{\left[{ }^{\circ} \mathbf{C}\right]}\end{array}$ & $\begin{array}{c}\mathbf{T}_{\mathbf{c}} \\
{\left[{ }^{\circ} \mathbf{C}\right]}\end{array}$ & $\begin{array}{c}\boldsymbol{\chi}_{\mathbf{c}} \\
{[\mathbf{\%}]}\end{array}$ \\
\hline 0.0 & 123.5 & 128.8 & 115.3 & 54.5 \\
\hline$\sim 1.5$ & 122.3 & 128.5 & 116.0 & 54.3 \\
\hline$\sim 3.0$ & 123.6 & 128.9 & 116.7 & 53.4 \\
\hline$\sim 4.5$ & 122.7 & 128.7 & 116.6 & 52.5 \\
\hline$\sim 6.0$ & 123.8 & 128.7 & 116.4 & 52.7 \\
\hline
\end{tabular}

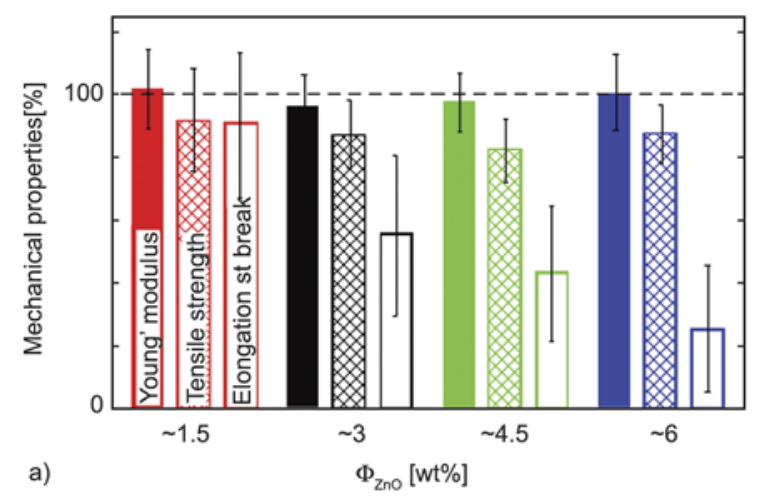

free volume of the MM samples. Actually, scarce improvements in the mechanical and barrier properties of $\mathrm{ZnO}$-filled nanocomposites have been reported even in case of good dispersion of the filler due to the low aspect ratio of the nanoparticles [15]. A more conclusive insight on the state of dispersion of the filler can be obtained through rheological measurements. In particular, linear viscoelastic analysis is an extremely sensitive tool to probe the material structure over various length scales, offering an integrated picture of composite samples with higher reliability of the results compared to other methods, based on the analysis of the mechanical and barrier properties, which are too sensitive to micron-scale inhomogeneity [16]. The time evolution of $G^{\prime}$ at $\omega=10^{-1} \mathrm{rad} / \mathrm{s}$ and the frequency-dependent moduli of neat polymer and nanocomposites at different filler content are shown in Figure 4.

Nanoparticles, either isolated or in the form of aggregates, may experience relevant Brownian motions in polymer melts provided that they are sufficiently small. Driven by particle-particle attraction, the filler flocculate in timescales which scale with the cubic power of the size of the aggregates [17]. Such structural rearrangements, if any, cause an enhancement of the elastic connotation during time, which eventually alters the relaxation spectrum in a characteristic way: both $G^{\prime}$ and $G^{\prime \prime}$ significantly increase at low frequency, the effect being more pronounced on the elastic component. It is important to observe that noticeable alterations are expected even for very low filler contents and poor polymer-particle affinity [18]. None of the rheological peculiarities of PNCs can be recognized in the MM, not even at relatively high $\mathrm{ZnO}$ contents. The behavior is rather reminiscent of that of conventional micro-compos-

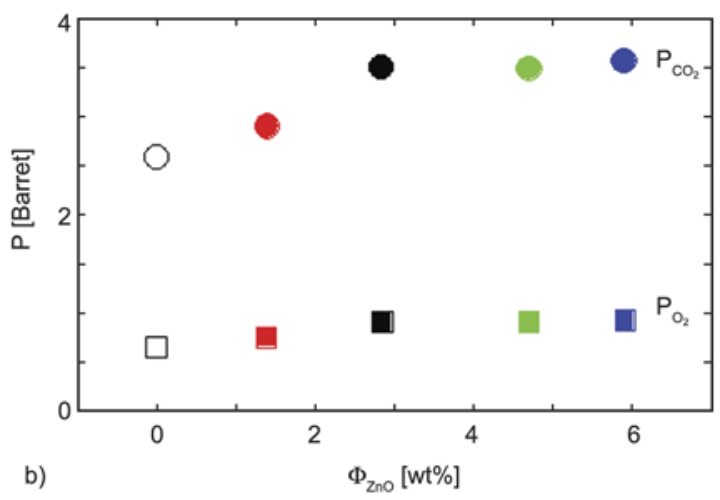

Figure 3. (a) Mechanical properties of the melt mixed PNCs at different $\Phi_{\mathrm{ZnO}}$ : Young's modulus, tensile strength and elongation at break. The values are normalized with respect to the neat matrix. (b) Barrier properties of the melt mixed PNCs at different $\Phi_{\mathrm{ZnO}}$ : permeability to oxygen (squares) and carbon dioxide (circles). 

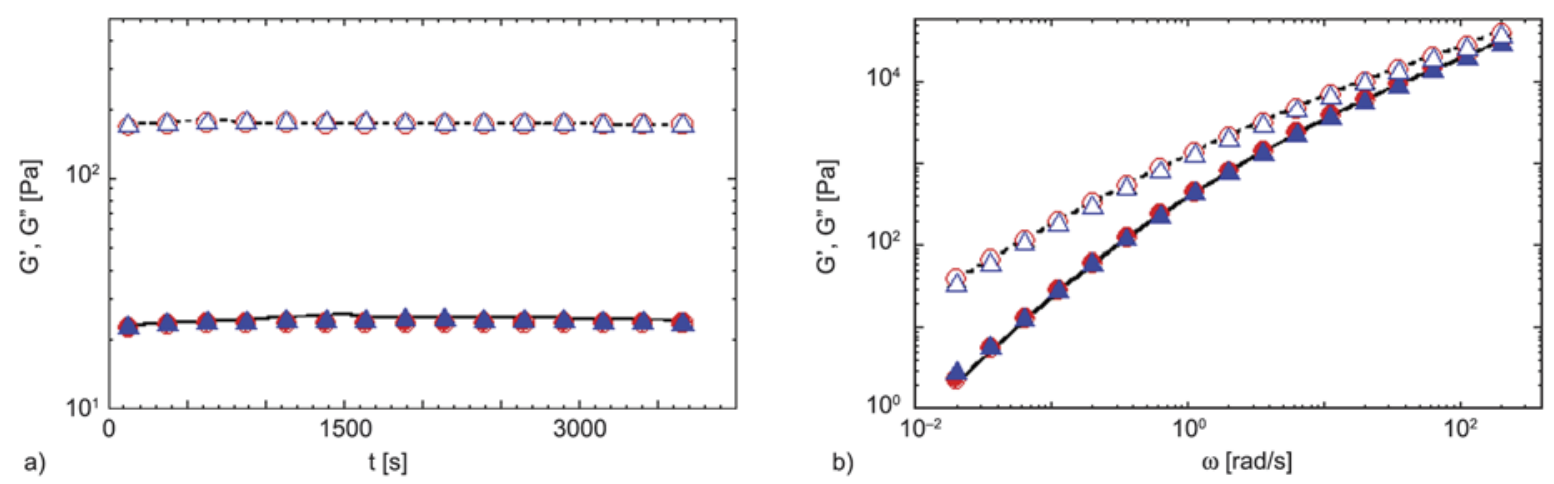

Figure 4. (a) Time evolution and (b) frequency-dependence of $G^{\prime}$ (full symbols) and $G^{\prime \prime}$ (empty symbols) of the PNCs at $\Phi_{\mathrm{ZnO}} \sim 1.5 \mathrm{wt} \%$ (red circles) and $\sim 6 \mathrm{wt} \%$ (blue triangles). Solid and dashed black lines represent $G^{\prime}$ and $G^{\prime \prime}$, respectively, of neat HDPE.

ites at low filler volume fractions, in which the particles are too big to move and rearrange in the melt and the volume of polymer perturbed by the filler is not sufficient to affect the overall relaxation spectrum $[19,20]$.

Although being a widespread route to distribute and disperse nanoparticles in the form of dry powders within polymer matrices, unless using targeted processing expedients, melt compounding is often inadequate in case of systems with very low polymerparticle affinity, such as the $\mathrm{HDPE} / \mathrm{ZnO}$ nanocomposites considered here. Aim of the next section is assessing the effectiveness of an alternative compounding method, which exploits the advantages of solution techniques eluding the issues related to the needing of specific solvents.

\subsection{Template-based approach}

The underlying idea of the proposed TB method is to make a dispersion of well dispersed $\mathrm{ZnO}$ nanoparticles to penetrate inside a microporous HDPE scaffold obtained by selective extraction of a sacrificial PEO phase blended with the HDPE. A prerequisite is that the starting HDPE/PEO blend exhibits a co-continuous morphology, in which PEO forms a space-spanning framework that interpenetrates the HDPE. A blend composition of $50 / 50 \mathrm{wt} \% / \mathrm{wt} \%$ has been selected for this purpose.

Once the PEO has been extracted, the remaining HDPE scaffold is dipped in a stable dispersion of isolated $\mathrm{ZnO}$ nanoparticles, which will hopefully remain trapped inside the polymer. In order to optimize the process, the HDPE scaffold should contain a thick network of tiny channels, i.e. the starting HDPE/PEO blend should exhibit a microstructure as fine as possible. In such a way, the trapped nanopar- ticles will finely distribute inside the host matrix. On the other hand, the penetration depth of the $\mathrm{ZnO}$ suspension inside the channels, which inversely scales with their diameter, must be preserved to ensure a homogeneous distribution along the sample thickness. Conciliating these two opposite requisites is a challenging task, which we have addressed through a judicial selection of the materials.

Adding plate-like nanoparticles to a polymer blend is a clever expedient to promote and stabilize fine co-continuous morphologies in immiscible polymer blends. Basing on recent results by our group, small amounts of C15A were used to refine the morphology of our blends [21]. The SEM micrographs showing the impact of the filler are reported in Figure 5. $\mathrm{C} 15 \mathrm{~A}$ induces a drastic downsizing of the polymer phases, and the HDPE scaffold remaining after the removal of PEO exhibits an irregular porous microstructure much finer than that of the unfilled sample.

Besides refining the morphology, the penetration of the suspension of $\mathrm{ZnO}$ nanoparticles inside the channels of the HDPE scaffold has to be ensured. For this purpose, wettability arguments are invoked. A good affinity between the liquid phase of the suspension and the polymer scaffold is required. The penetrating power of a liquid is equal to the distance which the liquid will penetrate a capillary tube of unit radius in unit time, when flowing under its own capillary pressure. Such a 'penetrativity' is also a function of the nature of the material composing the capillary and the liquid itself, being proportional to $\cos \theta$, where $\theta$ represents the contact angle [22]. To verify the relevance of the nature of the liquid medium, two different $\mathrm{ZnO}$ dispersions, one in water and the other in butyl acetate, have 


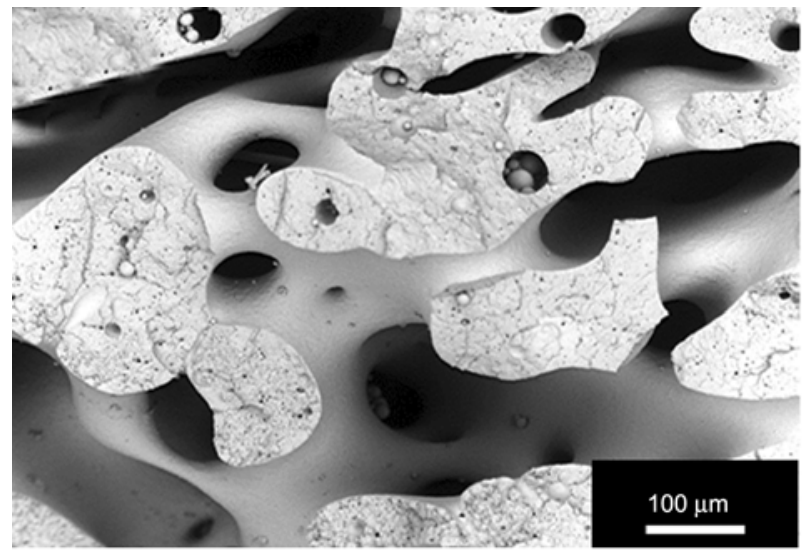

a)

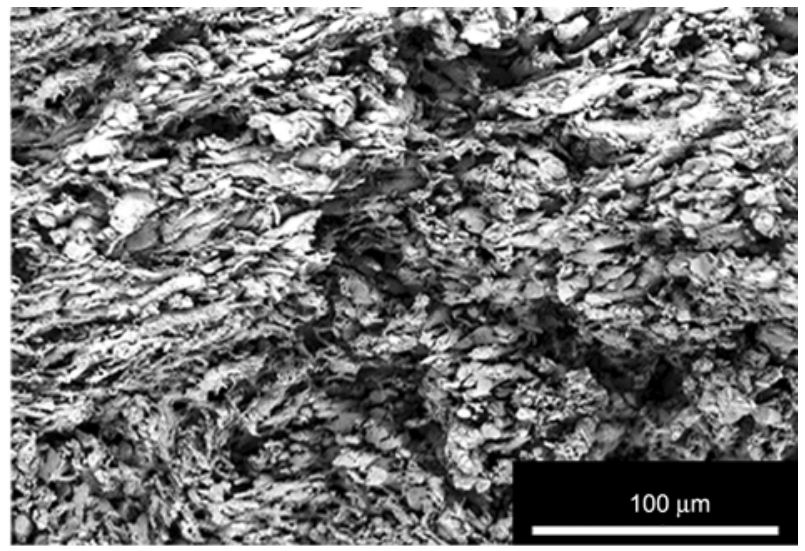

b)

Figure 5. SEM micrographs of (a) the neat HDPE/PEO blend and (b) the blend filled with $\Phi_{\mathrm{C} 15 \mathrm{~A}} \sim 1.5$ wt $\%$. For clarity, the cryo-fractured surfaces have been dipped in water to selectively remove the PEO phase.

been employed. The wettability of HDPE by the two liquids has been estimated by contact angle measurements, whose results are summarized in Table 2 (see also Figure 6).

The water contact angle is greater than $90^{\circ}$, hence water cannot penetrate inside the pores of the HDPE scaffold by capillary action. In contrast, the value of $\theta<<90^{\circ}$ of butyl acetate indicates a much higher propensity of this liquid to permeate the material. The EDS mapping of the fracture surfaces of the HDPE scaffolds confirm the presence of $\mathrm{ZnO}$

Table 2. Contact angle of water and butyl acetate on HDPE

\begin{tabular}{|l|c|}
\hline \multicolumn{1}{|c|}{ Probing liquid } & $\boldsymbol{\theta}$ \\
& {$\left[{ }^{\circ}\right]$} \\
\hline Water & $96.5 \pm 3.4$ \\
\hline Butyl acetate & $15.7 \pm 2.7$ \\
\hline
\end{tabular}

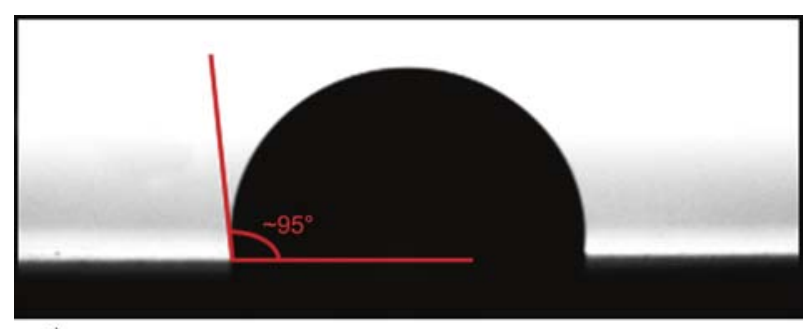

a)

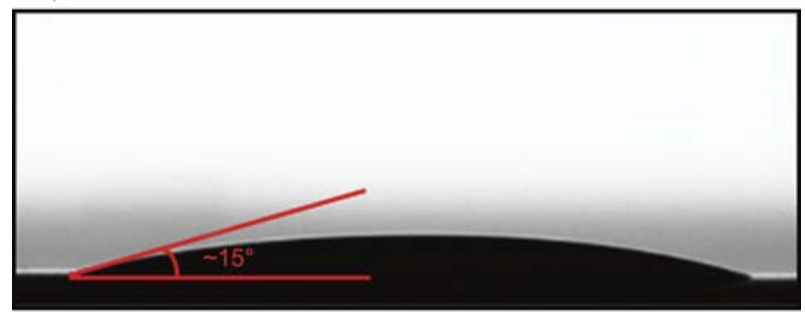

b)

Figure 6. Illustrative images of the contact angle measurements for HDPE films with (a) water and (b) butyl acetate nanoparticles in the porous sample dipped in the butyl acetate-based suspensions. It is worth noting that the EDS analysis was performed in the center of the disk, meaning that the $\mathrm{ZnO}$ suspension effectively penetrates deep inside the HDPE scaffold. On the contrary, the water-based dispersion cannot access the inner parts of the sample due to the unfavorable contact angle, and no signal related to the filler was detected (Figure 7).

More quantitative proofs of the presence of $\mathrm{ZnO}$ nanoparticles come from the TGA analyses performed on the HDPE scaffolds dipped into the two colloidal suspensions. As summarized in Table 3, a residual is noticed at high temperature, i.e. after the volatilization of the polymer, in both samples. Taking the residual of the C15A-containing HDPE scaffold as the reference, more than $2 \mathrm{wt} \%$ of $\mathrm{ZnO}$ nanoparticles remains trapped in the sample dipped in the butyl acetate-based suspension, compared to little more than $0.5 \mathrm{wt} \%$ of the one immersed in the water-based suspension.

Once the $\mathrm{ZnO}$ nanoparticles have been trapped in the HDPE scaffolds, the porous samples have been compacted as described in the Experimental section. The forth step of the procedure depicted in Figure 1 determines the eventual space arrangement of the $\mathrm{ZnO}$ nanoparticles in the TB samples. EDS analyses were performed to localize the filler. The SEM micrographs of the TB and MM samples with the $\mathrm{X}$-ray maps of the $\mathrm{Zn}$ are compared in Figure 8.

Although unable to overcome the strong cohesive forces which held together the primary $\mathrm{ZnO}$ nanoparticles within the aggregates, the MM route ensures a good distribution of the filler on micro-scale. On the contrary, the EDS mapping of the compacted TB 


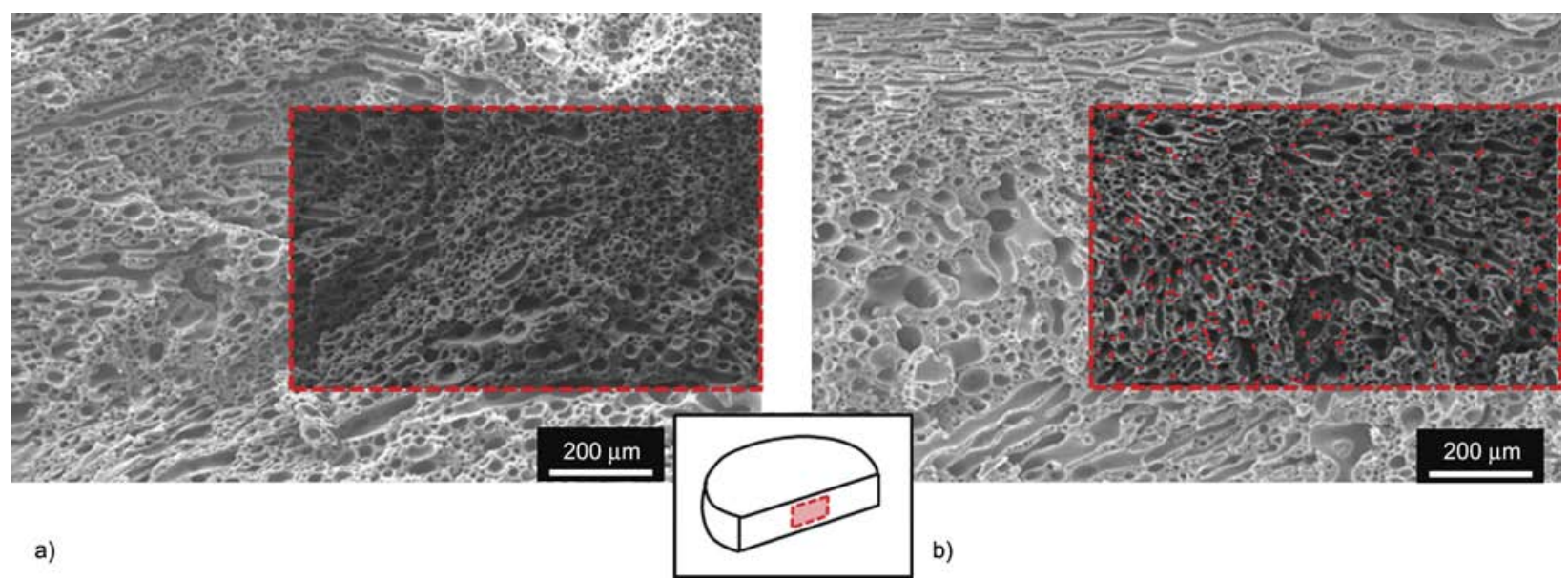

Figure 7. SEM micrographs with the X-ray map of zinc partially superimposed on it for the blends after immersion in the $\mathrm{ZnO}$ dispersion in (a) water and (b) butyl acetate

Table 3. Residual weight at $700^{\circ} \mathrm{C}$ of the HDPE scaffolds after immersion in $\mathrm{ZnO}$ dispersions in water and butyl acetate

\begin{tabular}{|l|c|}
\hline \multicolumn{1}{|c|}{ Sample } & $\begin{array}{c}\text { Residual } \\
{[\mathbf{w t} \% \mathbf{]}}\end{array}$ \\
\hline HDPE & 0.01 \\
\hline PEO & 1.71 \\
\hline HDPE/PEO & 0.78 \\
\hline HDPE (PEO extracted) & 0.15 \\
\hline HDPE/PEO+C15A & 2.32 \\
\hline HDPE+C15A (PEO extracted) & 1.68 \\
\hline HDPE+C15A+ZnO (water) & 2.37 \\
\hline HDPE+C15A+ZnO (butyl acetate) & 3.85 \\
\hline
\end{tabular}

sample reveals an inhomogeneous filler distribution, with ZnO-rich micro-channels intercalated with $\mathrm{ZnO}$-poor regions. This is in line with what we expected: the $\mathrm{ZnO}$ suspension can only penetrates the channels of the scaffold, but it cannot permeate their HDPE walls. As a result, micron-sized polymer domains devoid of filler will coexist with a con-

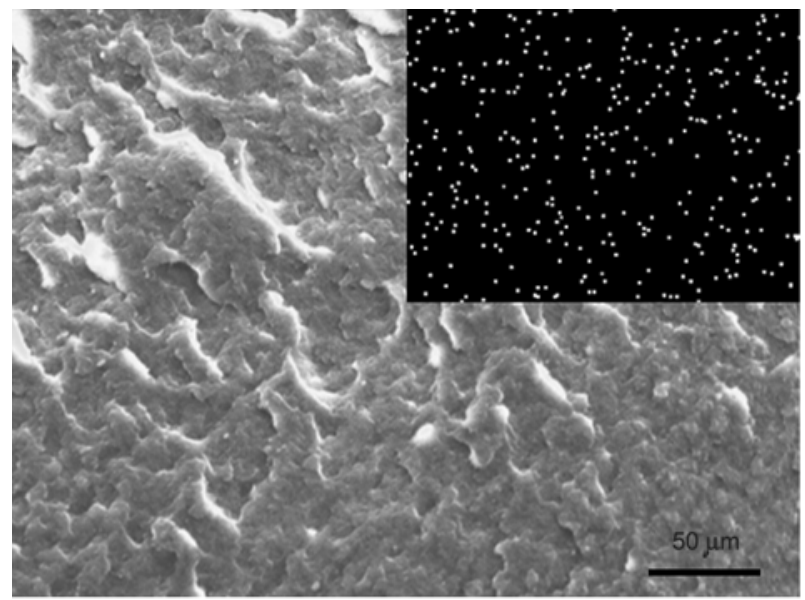

a) tinuous network of channels full of nanoparticles. Nonetheless, deriving from isolated $\mathrm{ZnO}$ nanoparticles firmly suspended in the liquid phase, the filler trapped in the TB samples is expected to be less aggregated than in the MM samples. Again, viscoelastic analysis is used as indirect and yet powerful tool to assess the state of dispersion of the particles. The time evolution of $G^{\prime}$ at $\omega=10^{-1} \mathrm{rad} / \mathrm{s}$ and the frequency-dependent moduli of the TB nanocomposite at about $2 \mathrm{wt} \%$ of $\mathrm{ZnO}$ are shown in Figure 9. Note that about $1.5 \mathrm{wt} \%$ of $\mathrm{C} 15 \mathrm{~A}$ remains trapped in the HDPE during the procedure to prepare the TB samples. A reference sample containing the same amounts of $\mathrm{ZnO}$ and $\mathrm{C} 15 \mathrm{~A}$ was then prepared by melt mixing and used for comparison.

Neither the time evolution of $G^{\prime}$ at low frequency nor the relaxation spectrum of the MM sample disclose the presence of the filler, confirming the ineffectiveness of the $\mathrm{MM}$ route in dispersing $\mathrm{ZnO}$ nano-

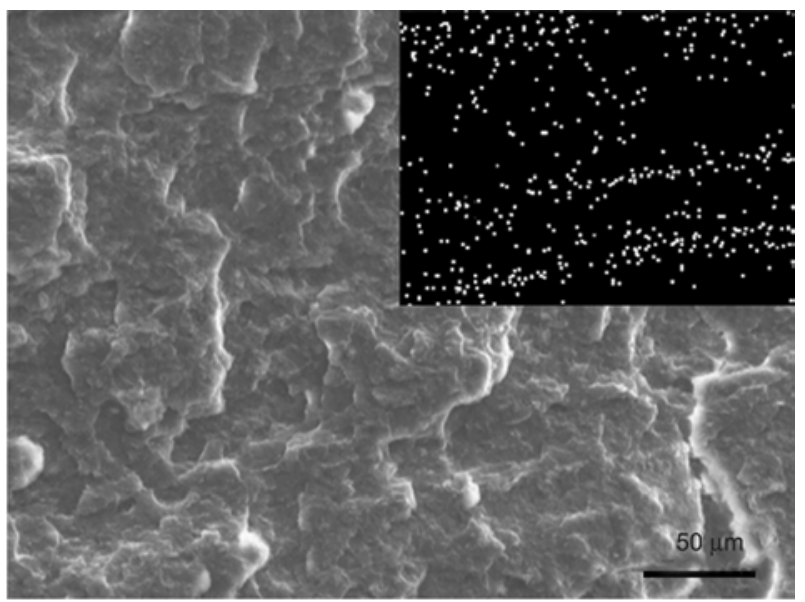

b)

Figure 8. SEM micrographs with the corresponding X-ray map of zinc in the inset for the samples prepared trough (a) the melt mixing and (b) template-based method 

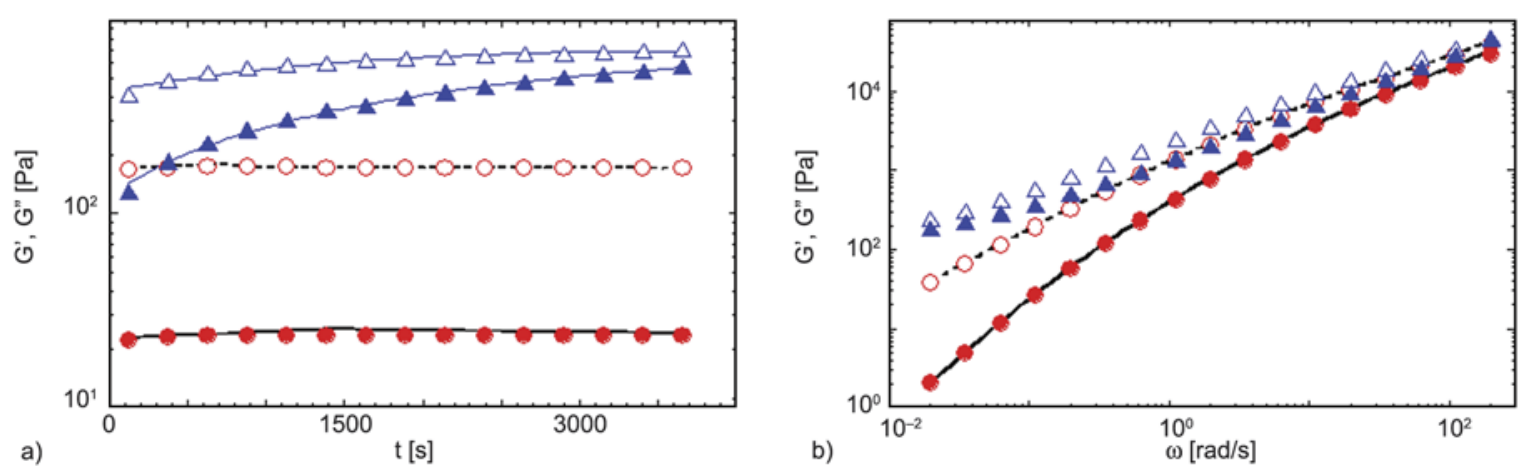

Figure 9. (a) Time evolution and (b) frequency-dependence of $G^{\prime}$ (full symbols) and $G^{\prime \prime}$ (empty symbols) of the PNCs prepared trough melt mixing (red circles) and template-based method (blue triangles) at $\Phi_{\mathrm{ZnO}} \sim 2 \mathrm{wt} \%$. Solid and dashed black lines represent $G^{\prime}$ and $G^{\prime \prime}$, respectively, of neat HDPE. Blue lines in a are guide for the eye.

particles within a non-polar matrix such as HDPE. Even possible synergistic effects with a secondary filler such as C15A have to be excluded. On the contrary, the filler strongly affects the viscoelasticity of the TB sample. Specifically, the growth of the lowfrequency moduli reflects the structural rearrangements of the nanoparticles, which flocculate in the melt driven by attractive forces. Such particle mobility has to be ascribed to a finer dispersion of the filler which allows the smaller aggregates to experience the Brownian motions essential for the emergence of the peculiar pseudo-solidlike behavior of well dispersed PNCs. The relaxation spectrum of the TB sample collected at the end of the time scan is shown in Figure 9b. The moduli get flat at low frequency, with a prominent effect on $G^{\prime}$ which increases of more than two order of magnitude with respect to the unfilled matrix despite the low amounts of filler considered. It is worth noting that similar alterations in the viscoelastic behavior cannot be found in the literature for HDPE-based nanocomposites unless performing modifications of the particle surface and/or adding suitable compatibilizers to reduce the chemical incompatibility between the polymer and the filler [23-25].

The viscoelastic behavior has been investigated also in the solid state by means of DMA (Figure 10).

Nanoparticles constrain the deformability of the amorphous fraction of HDPE in which they reside, improving the dynamic mechanical moduli. As DSC analyses exclude noticeable alterations of the crystalline structure of the HDPE (Table 4), the dynamic-mechanical properties primarily reflect the quality of the filler dispersion.

As in the melt state, the nanoparticles in the TB sample are much more effective in reinforcing the matrix. Again, the state of dispersion of the filler

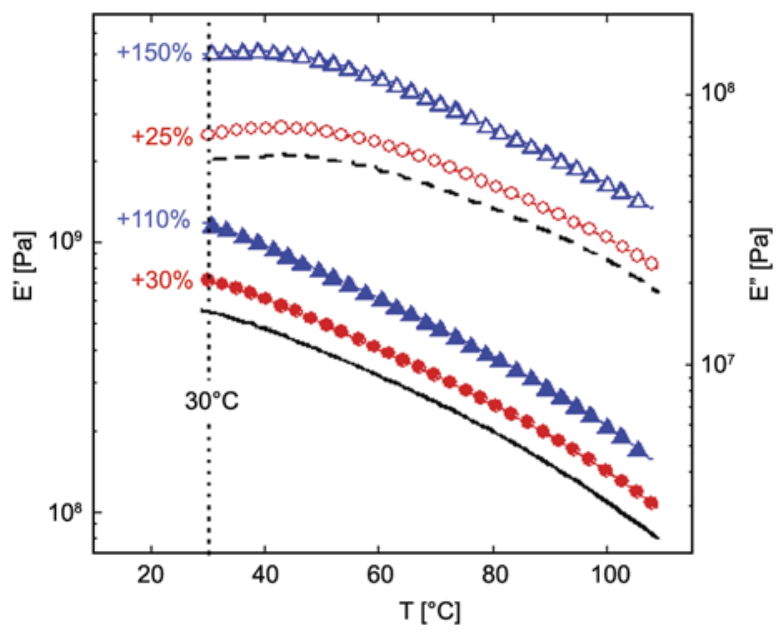

Figure 10. Temperature-dependence of $E^{\prime}$ (full symbols) and $E^{\prime \prime}$ (empty symbols) of the nanocomposite prepared trough melt mixing (red circles) and template-based method (blue triangles) at $\Phi_{\mathrm{ZnO}} \sim 2 \mathrm{wt} \%$. Solid and dashed black lines represent $E^{\prime}$ and $E^{\prime \prime}$, respectively, of neat HDPE

Table 4. Onset and peak melting temperatures, crystallization temperature and crystallinity of neat HDPE and nanocomposites

\begin{tabular}{|l|c|c|c|c|}
\hline Sample & $\begin{array}{c}\mathbf{T}_{\mathbf{m}, \mathbf{o n s e t}} \\
{\left[{ }^{\circ} \mathbf{C}\right]}\end{array}$ & $\begin{array}{c}\mathbf{T}_{\text {m,peak }} \\
{\left[{ }^{\circ} \mathbf{C}\right]}\end{array}$ & $\begin{array}{c}\mathbf{T c} \\
{\left[{ }^{\circ} \mathbf{C}\right]}\end{array}$ & $\begin{array}{c}\boldsymbol{\chi}_{\mathbf{c}} \\
{[\mathbf{\%}]}\end{array}$ \\
\hline $\mathrm{HDPE}$ & 123.5 & 128.8 & 115.3 & 54.5 \\
\hline $\mathrm{MM}$ & 124.6 & 128.4 & 116.3 & 53.2 \\
\hline $\mathrm{TB}$ & 122.6 & 128.7 & 116.1 & 53.5 \\
\hline
\end{tabular}

appears more important than its distribution on micron-scale in enhancing the macroscopic structural properties of PNCs.

Finally, the tensile behavior of the TB samples has been investigated. The Young's modulus, tensile strength and elongation at break are shown in Figure 11 taking the neat HDPE as a reference.

As consequence of the good particle dispersion, the modulus of the nanocomposite is noticeably higher 


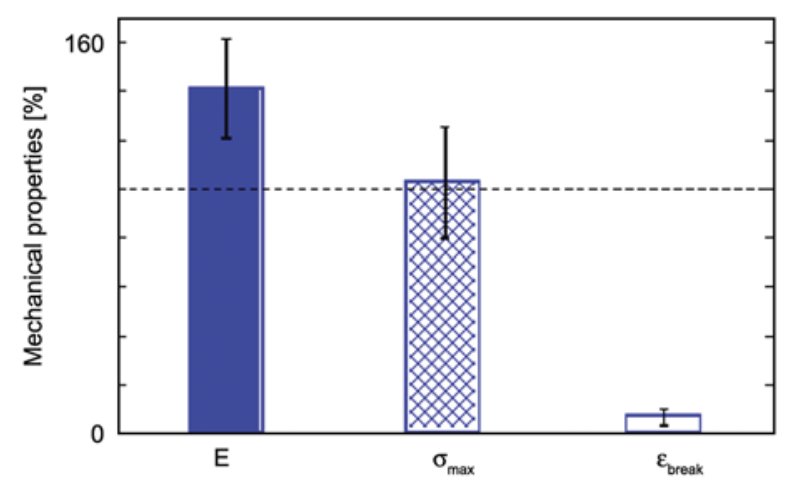

Figure 11. Mechanical properties of the TB sample: Young's modulus, tensile strength and elongation at break. The values are normalized with respect to the neat matrix.

than that of the matrix. However, such a strengthening is coupled with a remarkable loss in ductility, which reflects the inherent non-homogeneity of the sample. Specifically, besides the non uniform particle distribution, the ineludible presence of residual domains of PEO, which we estimate to be in the range $6-8 \mathrm{wt} \%$, makes the TB sample obviously brittle. Such a drawback must be taken into account in the analysis of pros and cons of the TB approach. Provided that a material embrittlement is passable, we argue that the proposed approach can be capitalized to impart specific functionality to the composite. As an example, using conductive fillers such as carbon nanotubes or graphene-based particles, very low percolation thresholds can be in principle attained, thus enhancing the electrical and/or thermal conductivity of the host polymer. A similar strategy underpins the double percolation concept, sometimes exploited in case of polymer blends with interfacially-located particles [26]. The latter condition can be difficult to realize, being dictated by cogent thermodynamic requirements. Differently, the TB approach in principle could result in low percolation thresholds in monophasic matrices irrespective of wettability considerations.

\section{Conclusions}

The efficiency of a novel template-based approach for the dispersion of hydrophilic nanoparticles within hydrophobic polymer matrices has been investigated using a system prepared by melt mixing as reference. The procedure envisages that a well dispersed $\mathrm{ZnO}$ nanoparticles suspension penetrates inside a microporous HDPE scaffold obtained by selective extraction of a sacrificial PEO phase blended with the HDPE. To finely distribute the nanoparticles inside the host matrix, two opposing requirements have been conciliated: (i) having a scaffold with a thick network of tiny channels and yet (ii) preserving the penetration depth of the $\mathrm{ZnO}$ suspension along the sample thickness. The goal has been reached through a judicial selection of the materials and the adoption of targeted expedients throughout the compounding procedure. Deriving from isolated $\mathrm{ZnO}$ nanoparticles firmly suspended in the liquid phase, the filler trapped in the microporous sample has resulted much better dispersed than in the melt mixed sample, and noticeable increases of the viscoelastic properties of the PNCs have been achieved. On the other hand, morphological analyses reveal $\mathrm{ZnO}$-rich domains surrounded by $\mathrm{ZnO}$ poor regions, indicating an inhomogeneous filler distribution on micron-scale. Despite a detrimental effect on the material ductility, the latter can be capitalized to minimize the amount of nanoparticles required to attain a certain improvement of functional properties. Although hard to scale up in an industrial context, our results demonstrate the possibility to realize spatially engineered polymer nanocomposites through the clever subtraction of volumes of materials where the nanoparticles can access in the course of the compounding.

\section{Acknowledgements}

This work has been supported by the Italian Ministry of University and Research (MIUR) through the PRIN 2009 prot. 2009WXXLY2_002.

\section{References}

[1] Sanchez C., Belleville P., Popall M., Nicole L.: Applications of advanced hybrid organic-inorganic nanomaterials: From laboratory to market. Chemical Society Reviews, 40, 696-753 (2011).

DOI: $10.1039 / \mathrm{COCS} 00136 \mathrm{H}$

[2] Jancar J., Douglas J. F., Starr F. W., Kumar S. K., Cassagnau P., Lesser A. J., Sternstein S. S., Buehler M. J.: Current issues in research on structure-property relationships in polymer nanocomposites. Polymer, 51, 3321-3343 (2010).

DOI: $10.1016 /$ j.polymer.2010.04.074

[3] Hiemenz P., Rajagopalan R.: Principles of colloid and surface chemistry. Marcel Dekker, New York (1997).

[4] Balazs A. C., Emrick T., Russell T. P.: Nanoparticle polymer composites: Where two small worlds meet. Science, 314, 1107-1110 (2006). DOI: $10.1126 /$ science. 1130557 
[5] Demir M. M., Wegner G.: Challenges in the preparation of optical polymer composites with nanosized pigment particles: A review on recent efforts. Macromolecular Materials and Engineering, 297, 838-863 (2012). DOI: 10.1002/mame.201200089

[6] Peponi L., Tercjak A., Martin L., Mondragon I., Kenny J. M.: Morphology-properties relationship on nanocomposite films based on poly(styrene-block-diene-blockstyrene) copolymers and silver nanoparticles. Express Polymer Letters, 5, 104-118 (2011). DOI: $10.3144 /$ expresspolymlett.2011.12

[7] Tyurin A., De Filpo G., Cupelli D., Nicoletta F. P., Mashin A., Chidichimo G.: Particle size tuning in silver-polyacrylonitrile nanocomposites. Express Polymer Letters, 4, 71-78 (2010).

DOI: 10.3144/expresspolymlett.2010.12

[8] Chow W. S., Leu Y. Y., Mohd Ishak Z. A.: Effects of SEBS-g-MAH on the properties of injection moulded poly(lactic acid)/nano-calcium carbonate composites. Express Polymer Letters, 6, 503-510 (2012).

DOI: $10.3144 /$ expresspolymlett.2012.53

[9] Nordström J., Matic A., Sun J., Forsyth M., MacFarlane D. R.: Aggregation, ageing and transport properties of surface modified fumed silica dispersions. Soft Matter, 6, 2293-2299 (2010).

DOI: $10.1039 / \mathrm{b} 921488 \mathrm{~g}$

[10] Agrawal M., Gupta S., Zafeiropoulos N. E., Oertel U., Häßler R., Stamm M.: Nano-level mixing of $\mathrm{ZnO}$ into poly(methyl methacrylate). Macromolecular Chemistry and Physics, 211, 1925-1932 (2010).

DOI: $10.1002 /$ macp.201000191

[11] Fidelus J., Piticescu R. R., Piticescu R. M., Lojkowski W., Giurgiu L.: Solvothermal synthesis of Co-doped $\mathrm{ZnO}$ nanopowders. Zeitschrift für Naturforschung B, 63, 725-729 (2008).

[12] Wunderlich B.: Macromolecular physics, Vol. 3. Academic Press, New York (1980).

[13] Baird D. G., Collias D. I.: Polymer processing principles and design. Butterworth-Heinemann, Newton (1995).

[14] Tjong S. C.: Structural and mechanical properties of polymer nanocomposites. Materials Science and Engineering R: Reports, 53, 73-197 (2006).

DOI: $10.1016 /$ j.mser.2006.06.001

[15] Hess S., Demir M. M., Yakutkin V., Baluschev S., Wegner G.: Investigation of oxygen permeation through composites of PMMA and surface-modified $\mathrm{ZnO}$ nanoparticles. Macromolecular Rapid Communications, 30, 394-401 (2009).

DOI: $10.1002 /$ marc. 200800732

[16] Galindo-Rosales F. J., Moldenaers P., Vermant J.: Assessment of the dispersion quality in polymer nanocomposites by rheological methods. Macromolecular Materials and Engineering, 296, 331-340 (2011).

DOI: $10.1002 /$ mame.201000345
[17] Romeo G., Filippone G., Russo P., Acierno D.: Effects of particle dimension and matrix viscosity on the colloidal aggregation in weakly interacting polymer-nanoparticle composites: A linear viscoelastic analysis. Polymer Bulletin, 63, 883-895 (2009).

DOI: $10.1007 / \mathrm{s} 00289-009-0176-2$

[18] Acierno D., Filippone G., Romeo G., Russo P.: Dynamics of stress bearing particle networks in poly (propylene)/alumina nanohybrids. Macromolecular Materials and Engineering, 292, 347-353 (2007).

DOI: $10.1002 /$ mame.200600386

[19] Acierno D., Filippone G., Romeo G., Russo P.: Rheological aspects of $\mathrm{PP}-\mathrm{TiO}_{2}$ micro and nanocomposites: A preliminary investigation. Macromolecular Symposia, 247, 59-66 (2007). DOI: $10.1002 / \mathrm{masy} .200750108$

[20] Dorigato A., Pegoretti A., Penati A.: Linear low-density polyethylene/silica micro- and nanocomposites: Dynamic rheological measurements and modelling. Express Polymer Letters, 4, 115-129 (2010). DOI: $10.3144 /$ expresspolymlett.2010.16

[21] Filippone G., Romeo G., Acierno D.: Role of interface rheology in altering the onset of co-continuity in nanoparticle-filled polymer blends. Macromolecular Materials and Engineering, 296, 658-665 (2011).

DOI: $10.1002 /$ mame. 201000343

[22] Washburn E. W.: The dynamics of capillary flow. The Physical Review, 17, 273-283 (1921).

DOI: $\underline{10.1103 / \text { PhysRev.17.273 }}$

[23] Sharif-Pakdaman A., Morshedian J., Jahani Y.: Influence of the silane grafting of polyethylene on the morphology, barrier, thermal, and rheological properties of high-density polyethylene/organoclay nanocomposites. Journal of Applied Polymer Science, 125, E305E313 (2012).

DOI: $10.1002 /$ app.36367

[24] Chae D. W., Kim K. J., Kim B. C.: Effects of silicalite1 nanoparticles on rheological and physical properties of HDPE. Polymer, 47, 3609-3615 (2006). DOI: $10.1016 /$ j.polymer.2006.03.053

[25] Majid M., Hassan E-D., Davoud A., Saman M.: A study on the effect of nano-ZnO on rheological and dynamic mechanical properties of polypropylene: Experiments and models. Composites Part B: Engineering, 42, 2038-2046 (2011). DOI: $10.1016 /$ j.compositesb.2011.04.043

[26] Sumita M., Sakata K., Hayakawa Y., Asai S., Miyasaka K., Tanemura M.: Double percolation effect on the electrical conductivity of conductive particles filled polymer blends. Colloid and Polymer Science, 270, 134-139 (1992). DOI: $10.1007 / \mathrm{BF} 00652179$ 